\title{
Synoptic-scale precursors of landslides in the western Himalaya and Karakoram
}

\section{Article}

\section{Accepted Version}

Creative Commons: Attribution-Noncommercial-No Derivative Works 4.0

Hunt, K. ORCID: https://orcid.org/0000-0003-1480-3755 and Dimri, A. P. (2021) Synoptic-scale precursors of landslides in the western Himalaya and Karakoram. Science of the Total Environment, 776. 145895. ISSN 0048-9697 doi: https://doi.org/10.1016/j.scitotenv.2021.145895 Available at https://centaur.reading.ac.uk/96224/

It is advisable to refer to the publisher's version if you intend to cite from the work. See Guidance on citing.

To link to this article DOI: http://dx.doi.org/10.1016/j.scitotenv.2021.145895

Publisher: Elsevier

All outputs in CentAUR are protected by Intellectual Property Rights law, including copyright law. Copyright and IPR is retained by the creators or other copyright holders. Terms and conditions for use of this material are defined in the End User Agreement.

\section{www.reading.ac.uk/centaur}

\section{CentAUR}

Central Archive at the University of Reading 
Reading's research outputs online 


\title{
Synoptic-scale precursors of landslides in the western Himalaya and
}

\section{Karakoram}

\author{
Kieran M. R. Hunt ${ }^{1}$ and A. P. Dimri ${ }^{2}$ \\ ${ }^{1}$ Department of Meteorology, University of Reading, UK \\ ${ }^{2}$ School of Environmental Sciences, Jawaharlal Nehru University, Delhi, India
}

\begin{abstract}
In the Upper Indus Basin (UIB), precipitation associated with synoptic-scale circulations impinges on the complex and steep orography of the western Himalaya and Karakoram. Heavy rainfall often falls over the foothills, frequently triggering landslides there. This study explores the role of these synoptic-scale circulations extratropical western disturbances (WDs) and tropical depressions (TDs) - in producing the conducive conditions necessary to trigger landslides, using data from the NASA Global Landslide Catalog and WD and TD track databases.

During the winter (October to April), UIB landslides peak in February and occur at a rate of 0.05 day $^{-1}, 61 \%$ of which are associated with the passage of a WD. They are most common when a WD is located within a few hundred kilometres of $30^{\circ} \mathrm{N}$, and significantly rarer if the WD is north of $40^{\circ} \mathrm{N}$. WDs provide moist southwesterly flow from the Arabian Sea (AS) and Mediterranean Sea to the UIB, resulting in large-scale precipitation, but landslide probability is not related to WD intensity. Non-WD winter landslides are associated with small-scale orographic precipitation that we hypothesise is due to cloudbursts.

During the summer (May to September), UIB landslides peak in August and occur at a rate of 0.11 day $^{-1}$, $60 \%$ of which are associated with TD activity. Many of these TDs are found over central India, slightly south of the climatological monsoon trough, where they provide strong monsoonal southeasterlies to the UIB flowing along the Himalayas. Increased landslide frequency is also associated with TD activity over the southern Bay of Bengal (BoB), and it is hypothesised that this is related to monsoon break conditions. Landslide frequency is significantly correlated with TD intensity. Non-TD landslides are associated with a northwestward extension of the monsoon trough, providing southeasterly barrier flow to the UIB.

Implications for forecasting and climate change are discussed.
\end{abstract}

Keywords: landslides; Indus Basin; western disturbances; depressions; precipitation; moisture flux 


\section{Introduction}

2 About $75 \%$ of all global landslides occur in Asia; of these, the majority happen along the mountain ranges

4 of south Asia: the Himalaya, the Hindu Kush, and the

5 Karakoram (Froude and Petley, 2018). Along most

6 of the Himalaya, the seasonality of landslides is de-

termined by the arrival and withdrawal of the sum-

mer monsoon (Kirschbaum et al., 2010; Petley, 2012).

9 However, further west, over the western Himalaya and

Karakoram, the influence of the monsoon is less important, and landslides become increasingly frequent in the winter and spring months (Atta-ur Rehman et al., 2011; Saleem et al., 2020). This results in a complex seasonality of landslides in the Upper Indus Basin (UIB) (Fig. 1) which makes adequate preparation and mitigation a challenge. Over the UIB, landslides have been responsible for changing the course of Indus tributaries (Hewitt, 1998), significant loss of life (Kirschbaum et al., 2012; Froude and Petley, 2018) and significant socioeconomic damage (Atta-ur Rehman et al., 2011).

Weather patterns over the Indus Basin are highly seasonal. In the winter (October to April, i.e. outside of the monsoon season), mean low-level winds are weakly westerly with a strong upper-level westerly jet. Within this jet, extratropical cyclones, known as western disturbances (WDs), are embedded, and are responsible for most winter precipitation in this region. In summer (May to September), the westerly jet migrates poleward and the frequency of WDs reduces dramatically. Instead, precipitation usually occurs as a result of northwestward extensions of monsoon activity. Tropical depressions (TDs) are responsible for about half of summer monsoon precipitation, though the fraction is generally slightly lower over the Indus Basin (Hunt and Fletcher, 2019). Climatological precipitation, which is greatest along the foothills, is shown for both winter and summer in the middle panels of Fig. 2. Many previous studies agree that heavy rainfall is the most important environmental precursor to landslides globally (Kirschbaum et al., 2012, 2015), especially over south Asia (Dahal et al., 2008; Kirschbaum et al., 2010; Zhang et al., 2019), where intensity-duration thresholds are usually used as predictors with some success (Sengupta et al., 2010; Kirschbaum et al., 2011). It is also important that there has been significant antecedent rainfall so that the soil is either nearly or totally saturated (Gabet et al., 2004; Ahmed et al., 2014; Kumar et al., 2014), although the relative importance is highly sensitive to surficial geology. A few case studies of particularly significant flooding and landslide events across the western Himalaya have looked for meteorological precursors. For example, the heavy rainfall that caused extensive flash flooding and landslides over Jammu and Kashmir in 2010 were ascribed to multiple mesoscale convective storms that were steered into the region by favourable mid-tropospheric jet. These coincided with southerlies from the Arabian Sea (AS), which provided the moisture required for unusually sustained, heavy rainfall (Kumar et al., 2014). Analysis of the 2013 Uttarakhand floods and associated landslides found the antecedent rainfall came about as a strong WD interacted with a TD, providing very large southeasterly moisture flux to the orography (Mishra, 2015; Chevuturi and Dimri, 2016; Hunt et al., 2020a). More generally, moist southwesterlies embedded in WDs (Dimri et al., 2015) provide heavy rainfall and sometimes cloudbursts due to conjugate factors of convective triggering and orographic locking (Dimri et al., 2017).

Heavy rainfall is not the only important ingredient for landslides. As mentioned earlier, the soil and underlying rock must usually be very close to field capacity before the shear strength within a slope is reduced enough for landslides to be initiated. In some 

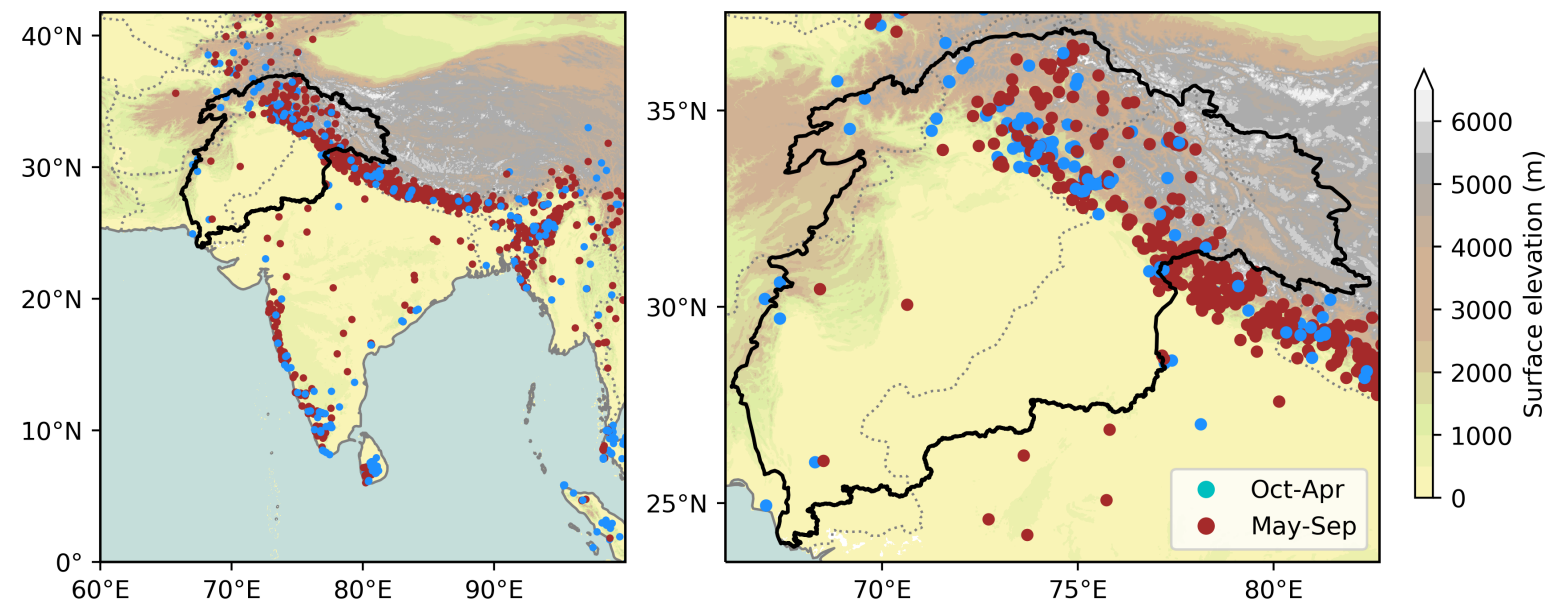

Figure 1: Locations of landslides in the NASA GLC, covering 2007-2015. Blue dots mark landslides occurring between October and April; brown dots mark those occurring between May and September. The thick black line marks the boundary of the Indus Basin. Left: over the Indian peninsula and surrounding area; right: over the Indus Basin (marked in black).

locations may only be possible near the end of the wet season. For example, Gabet et al. (2004) found that a mean seasonal rainfall of $860 \mathrm{~mm}$ was required to get the regolith up to field capacity over Nepal and as a result, landslides peak there during the latter part of the summer monsoon. Even then, several environmental and geological factors must be taken into consideration. A review of global landslide research by Zhang et al. (2019) noted that slope gradient and underlying lithology were important in determining landslide size, whereas climatological rainfall was important in determining their location. Looking specifically at the UIB, a detailed study by Ahmed et al. (2014) explored factors controlling landslide susceptibility. They separated their analysis into environmental and causative risk factors. For environmental factors, they found that UIB landslides were most common on slopes with an angle between $30^{\circ}$ and $45^{\circ}$, at elevations between 2 and $4 \mathrm{~km}$. They also found a significant, though less important, relationship with slope aspect, finding that landslides were most common on slopes facing a heading of $226^{\circ}-$ $270^{\circ}$ - this is the orientation at which moist southwesterlies, often induced by passing WDs, would strike the orography head on. Ghosh et al. (2011) found similar results for the eastern Himalaya near Darjeeling, also highlighting the role of lithology, geomorphology, and 99 land use. These environmental factors are useful in un- ${ }_{100}$ derstanding the spatial patterns of landslide frequency, and thus are important in reducing false alarms. How- ${ }_{102}$ ever, being quasi-static, they are not useful for predict- ${ }_{103}$ ing when landslides might occur. Causative risk factors, on the other hand, provide temporal information and are thus potentially useful for predictions through an understanding of the underlying meteorology.

Despite the global and regional linkages with heavy rainfall and the case studies discussed earlier, very little work has been done to assess meteorological precursors to landslides in south Asia over climatological sample sizes. Kamae et al. (2017) found that atmospheric rivers were important in providing the heavy precipitation needed to trigger landslides over East Asia. Mamadjanova et al. (2018) found that moist westerlies were an important precursor for landslides in Uzbekistan and assessed the relative role of cyclonic circulations. Saleem et al. (2020) noted that WDs play an "equal role" to monsoonal rainfall in instigating landslides over northern Pakistan.

A full understanding of the meteorological precursors of landslides is a vital component in constraining their sensitivity to climate change, in particular be- 
cause synoptic-scale systems contribute a majority of average precipitation and extreme precipitation events to the Himalaya (Hunt et al., 2018b, 2019b; Hunt and Fletcher, 2019). For example, monsoon depressions are projected to fall in frequency, but move poleward (Sandeep et al., 2018); and WDs are projected to bring more intense rainfall (Hunt et al., 2020b), though the fate of their frequency in a changing climate remains an open question (Ridley et al., 2013; Krishnan et al., 2018; Hunt et al., 2019a). Correspondingly, Kirschbaum et al. (2020) found a projected increase in landslides over the Himalaya when they applied a landslide hazard model to global climate model output. Increases in the observational record have been found for the central Himalaya (Petley et al., 2007) and the Hindu-Kush Himalaya (You et al., 2017); though Petley et al. (2007) attributed the increase in their record to be due to increased construction and infrastructure work on slopes.

The key research questions to be addressed, therefore, are:

- What role does the presence of synoptic-scale systems, such as TDs and WDs, play in initiating landslides over the western Himalaya and Karakoram, in particular over the UIB?

- Are there other weather patterns that act as important precursors?

- Can this information be used to improve landslide predictability?

\section{Data and methodology}

\subsection{NASA Global Landslide Catalogue}

In this study, we use landslide data from the NASA Global Landslide Catalogue (GLC, Kirschbaum et al., 2010, 2015). The GLC is a catalogue of precipitationtriggered landslides identified from sources including news reports, disaster databases, and research papers. Triggers are determined from the source material itself. The catalogue contains over 11000 entries from 2007 to 2015,327 of which occur in the UIB. Uncertainty in recorded location is also included within the GLC. Of the 327 UIB landslides, $88 \%$ have a location uncertainty of less than $50 \mathrm{~km}, 70 \%$ within $25 \mathrm{~km}$, and $45 \%$ within $10 \mathrm{~km} .11 \%$ lack spatial uncertainty data. Each landslide is assigned a UTC day-of-occurrence, but uncertainty in temporal information is not provided. We do not expect spatiotemporal uncertainties to significantly affect our results. However, it is worth noting here that the nature of the sources used in the GLC impart a bias towards populated regions - where landslides are more likely to be reported - and hence towards more anthropogenic triggers. The GLC also includes a measure of 'size' for each landslide, ranging from small (shallow; affecting one hillslope; minimal or no infrastructure damage) to very large (multiple events affecting an entire region; catastrophic damage to infrastructure; often encompassing whole villages). Of the 327 UIB landslides in the catalogue, 14 are rated small, 284 medium, 26 large, and 3 very large. For more information on uncertainty and size measures, the reader is encouraged to read Secs. 2.1 and 2.2 of Kirschbaum et al. (2015).

\subsection{ERA-Interim}

To analyse the structure of dynamical fields and moisture in the atmosphere, we use the European Centre for Medium-Range Weather Forecasts Interim reanalysis (ERA-I; Dee et al., 2011). All fields are available at six-hourly intervals with a horizontal resolution of T255 ( $\sim 78 \mathrm{~km}$ at the equator), with the three-dimensional fields further distributed over 37 vertical levels spanning from the surface to $1 \mathrm{hPa}$. Data are assimilated into the forecasting system from a variety of sources, 
including satellites, ships, buoys, radiosondes, aircraft, and scatterometers. In this study, we use wind and humidity data at all pressure levels to compute verticallyintegrated moisture flux.

\subsection{GPM-IMERG}

For our precipitation dataset, we use the gridded surface product Integrated Multi-Satellite Retrievals for GPM (IMERG; Huffman et al., 2015). This has global coverage at a half-hourly, $0.1^{\circ}$ resolution, starting June 2000 and continuing to the present day. Over the tropics, IMERG primarily ingests retrievals from (for 20002014) the now-defunct Tropical Rainfall Measuring Mission (TRMM; Kummerow et al., 1998, 2000) 13.8 GHz precipitation radar and microwave imager (Kozu et al., 2001) and (for 2014-) the Global Precipitation Measurement (GPM; Hou et al., 2014) Ka/Ku-band dualfrequency precipitation radar. Where an overpass is not available, precipitation is estimated by calibrating infrared measurements from geostationary satellites. While GPM-IMERG performs well when compared against gauge-based products, performance falls at higher elevations or when quantifying extreme rainfall events (anj; Prakash et al., 2018). Given the nature of our study, this introduces some uncertainty into our results. As such, all key results are additionally verified using precipitation output from the Indian Monsoon Data Assimilation and Analysis (IMDAA) reanalysis project (Ashrit et al., 2020), as high resolution reanalyses have been shown to perform well in the Indus Basin (Baudouin et al., 2020). Full half-hourly resolution is used in the antecedent rainfall analysis in Fig. 8, but daily accumulations (00UTC-00UTC) are used for the composite analysis in Figs. 2 and 6.

\subsection{Track databases}

We use the database of WD tracks from Hunt et al. ${ }_{228}$ (2018a) in this study. Using six-hourly ERA-Interim ${ }_{229}$ data, they tracked WDs by computing the mean relative $\quad 230$ vorticity in the 450-300 hPa layer, then performed a spectral truncation at T63 to filter out short-wavelength noise. They then identified positive-definite vorticity regions within this field and determined the centroid location for each one. These centroids were then linked in time, subject to constraints in distance and steering winds, to form candidate WD tracks. Finally, those candidate tracks that did not pass through South Asia $\left[20^{\circ} \mathrm{N}-36.5^{\circ} \mathrm{N}, 60^{\circ} \mathrm{E}-80^{\circ} \mathrm{E}\right]$, have a lysis to the east of their genesis, or last at least 48 hours were rejected. This catalogue is publicly available at http://dx.doi . org/10.5285/233cf64c54e946e0bb691a07970ec245.

We use the database of TD tracks from Hunt and Fletcher (2019) in this study. The core of the algorithm used for this is identical to that used to develop the WD catalogue above, except the input is the truncated $900-800 \mathrm{hPa}$ relative vorticity field. There is no domain filtering at the end but tracks shorter than 48 hours are still rejected. This catalogue is publicly available at http://gws-access.jasmin. ac.uk/public/incompass/kieran/track_data/lpstracks_v1_1979-2014.csv. Note that in this study, tropical depression is used as a collective term to refer to monsoon low-pressure systems, monsoon depressions, tropical lows, and tropical storms.

\section{Results}

As discussed in the introduction, the overwhelming majority of landslides in the Himalaya occur after heavy precipitation. To show what form it takes, mean precipitation is plotted for days on which a landslide occurs in the Upper Indus Basin (UIB; an area that con229 231 232 233 234 235 236 237 238 239 240 241 242 243 244 245 246 247 248 249 250 251 252 253 254 255 

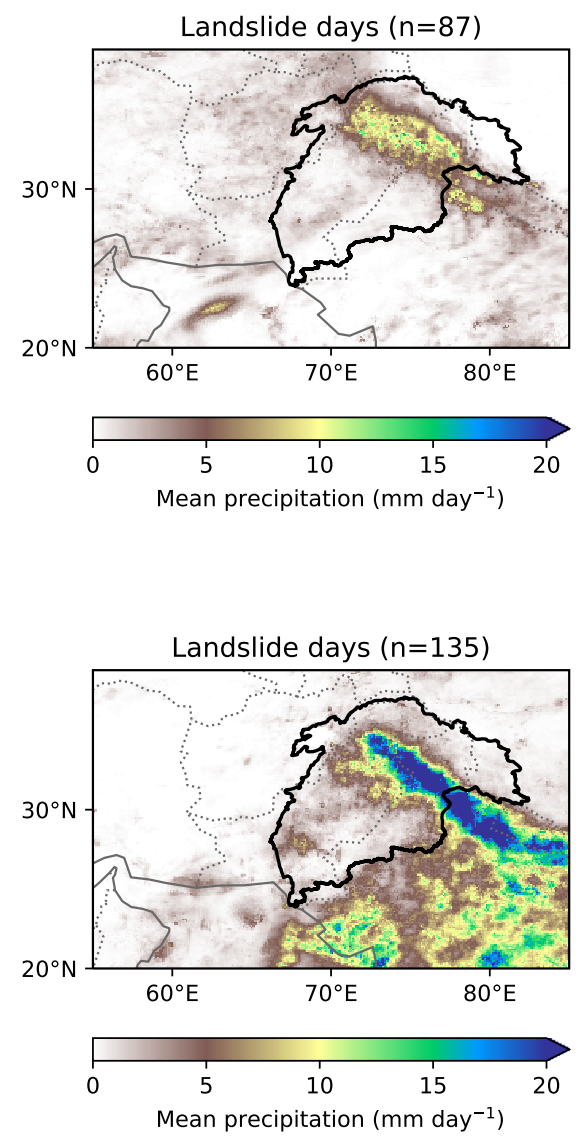

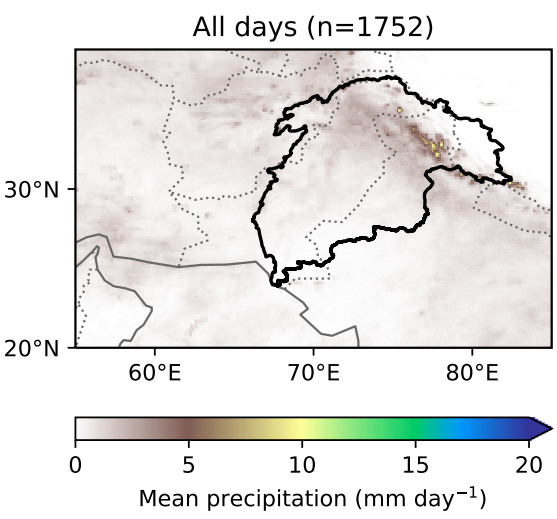

(a)

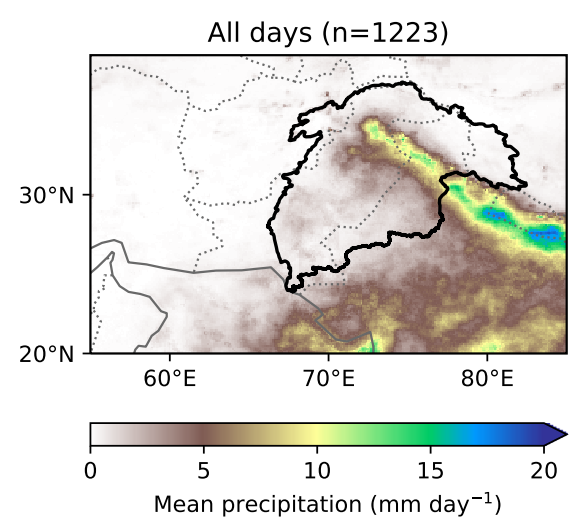

(b)
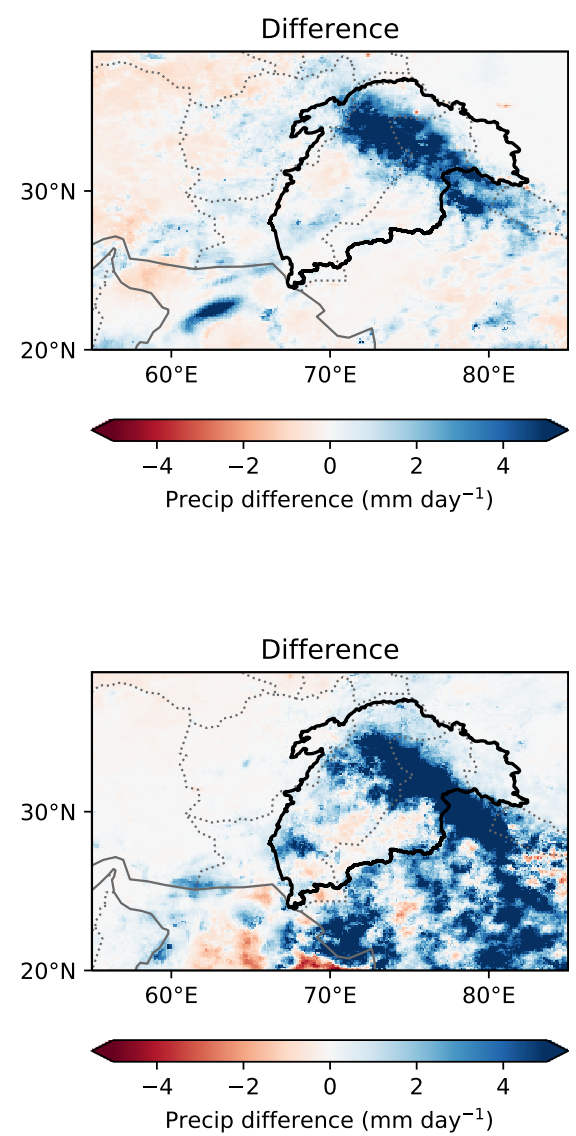

Figure 2: Mean precipitation for days in (a) October-April and (b) May-September in which a landslide occurs in the UIB (left panels) compared with the mean for all days in the same period (2007-2015, middle panels). Difference plots shown on the right. Data from GPM-IMERG. The solid black line marks the edge of the Indus River Basin. The same figure, computed using IMDAA reanalysis, is shown in supplementary Fig. S1.

tains both the western Himalaya and the Karakoram)

in Fig. 2. For comparison, the precipitation climatol-

ogy is shown, and the results are partitioned by season

into the summer monsoon (May through September)

and winter (October through April). Before proceed-

ing, we remind the reader of the inherent uncertainties

and biases present in the landslide dataset, as discussed

in Sec. 2.1. Landslides are approximately twice as fre-

quent in the UIB during the summer monsoon (occur-

ring on $11 \%$ of days) as during the winter (occurring

on $5 \%$ of days); this contrasts the central and east-

ern Himalaya, for which landslides almost exclusively

occur during the summer monsoon (e.g. Kirschbaum

et al., 2010). For a complete understanding of pre-

cursor weather, we must, therefore, consider the syn- optic dynamics at work in both seasons. Computing the dispersion statistic, $\sigma$, (not shown), we find that UIB landslides are highly temporally clustered in the summer season $(\sigma \sim 4)$, and quite temporally clustered in the winter season $(\sigma \sim 1.5)$. It is evident from Fig. 2 that the precipitation is much heavier on landslide days in both seasons (in some places averaging $20 \mathrm{~mm}$ day $^{-1}$ more than the climatology). For events that occur during the summer monsoon (Fig. 2(b)), the anomalous precipitation has a footprint that extends southeast, far beyond the UIB, over the Indian subcontinent. This suggests that the anomalous rainfall over the UIB during the monsoon probably comes about as a result of enhanced monsoon activity, either through an active phase or through the passage of a monsoonal 
tropical depression (TD). Disentangling active phases of the monsoon from TD activity is difficult, and some authors (e.g. Rajeevan et al., 2010) consider them to be synonymous; however, TDs have been shown to provide considerable monsoon rainfall to northwest India and Pakistan if they sufficiently penetrate the subcontinent or start in the Arabian Sea (Hunt and Fletcher, 2019). It is reasonable, therefore, to assume that the source of anomalous precipitation over the UIB during summer monsoon landslide is increased TD activity. For winter landslides (Fig. 2(a)), the footprint of anomalous precipitation is, for the most part, confined to the UIB, suggesting either a local source, or a more distant source capable of providing significant moisture flux. WDs are the predominant source of both climatological precipitation and heavy precipitation events over the winter UIB (e.g. Hunt et al., 2018b), but there are other important sources such as non-WD cloudbursts and orographic precipitation (Dimri, 2006).

\subsection{Synoptic controls on landslide fre- quency}

We will now test the hypothesis that TDs and WDs are responsible for the majority of monsoon and winter landslides respectively in the UIB. Using the track catalogues described in Sec. 2.4, we find the nearest TD or WD to each UIB landslide event. To identify the nearest TD and WD, all track points for the respective systems logged on the UTC day on which the landslide occurred are considered. Among those, the point (one for each type of system) with the shortest great-circle distance to the landslide is used. The results that follow in this study are not qualitatively sensitive to the choice of temporal window. The distances between landslide and system are tallied by month in Fig. 3. WDs have a strong annual cycle and are most common in the winter, and this projects strongly onto their relationship with UIB landslide frequency (Fig. 3(a)). From November through May (narrowly excepting April), a WD is present within $5000 \mathrm{~km}$ of a majority of UIB landslides. Integrated over the non-monsoon months of October to May, this value is $61 \%$, of which $45 \%$ occur within $2000 \mathrm{~km}$. TDs also have a strong annual cycle, although they do continue in significant numbers outside the monsoon. Again, this projects strongly onto their relationship with UIB landslide frequency (Fig. 3(b)), a TD is present with $5000 \mathrm{~km}$ of $60 \%$ of all UIB landslides occurring between May and September, of which it is within $2000 \mathrm{~km} 35 \%$ of the time. There is a secondary peak of TD contribution in February and March, due to pre-monsoon tropical cyclones in the Arabian Sea.

So, we have seen that landslide hazard in the UIB has a relatively strong dependence on both the presence and proximity of synoptic circulations such as WDs and TDs. It is therefore reasonable to assume that landslides are also sensitive to system location. For example, if a WD is too far east, then the associated southerly moisture flux will impinge on the central or eastern Himalaya instead of the western Himalaya, and the chance of a landslide in the UIB will not be significantly increased. To test this hypothesis, we use the extract from the TD and WD track catalogues all systems that occur during the GLC period (2007-2015). Individual track points are then binned into $2^{\circ} \times 2^{\circ}$ gridboxes, and the mean frequency of UIB landslide occurrence given a system present in that gridbox is computed. These maps, filtered by their respective seasons (May-September for TDs; October-April for WDs) are shown in Fig. 4. The map for WDs (Fig. 4(a)) has several key features. Firstly, we see that the latitude of the WD, tightly controlled by the latitude of the subtropical westerly jet in which it is embedded (Dimri and Chevuturi, 2016), is very important in determining whether the likelihood of a UIB landslide is increased or 


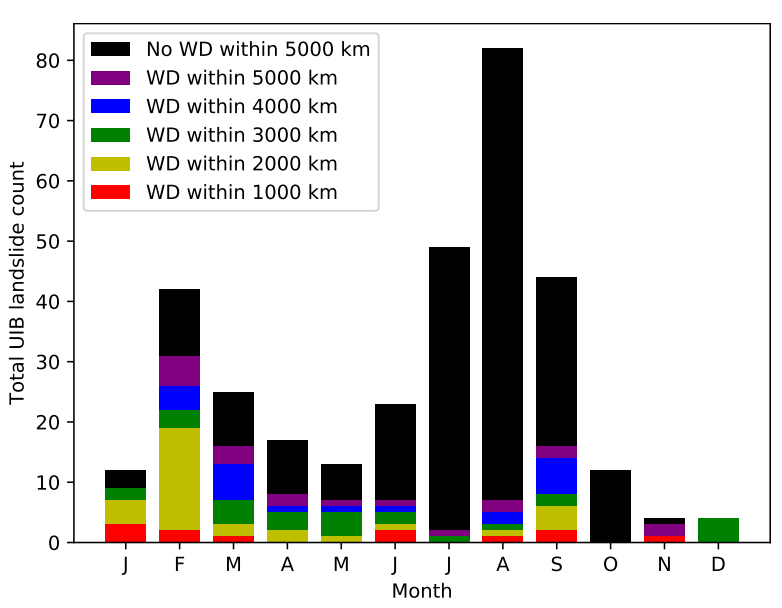

(a) western disturbances

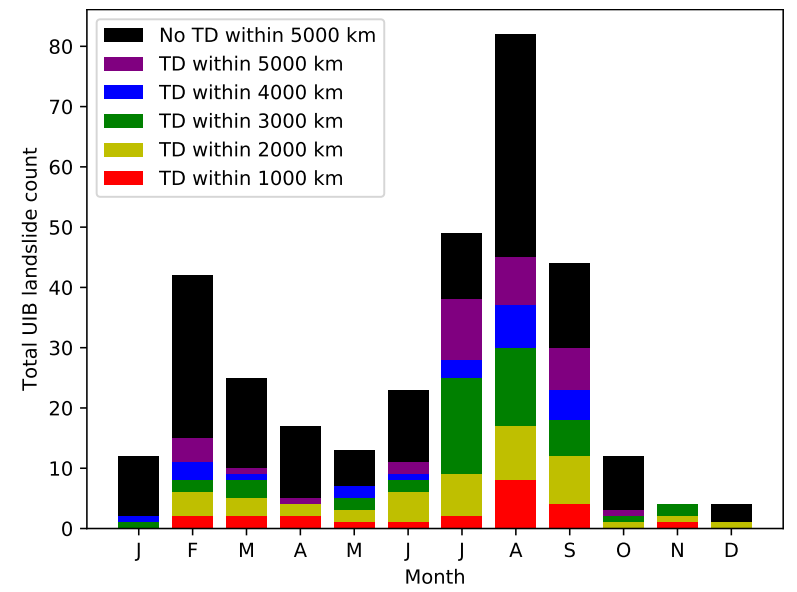

(b) tropical depressions

Figure 3: Monthly frequencies of landslides in the UIB. Bars coloured by proximity of (a) western disturbance and (b) tropical depression. Black indicates no system present within $5000 \mathrm{~km}$ of the landslide.

(a) western disturbances

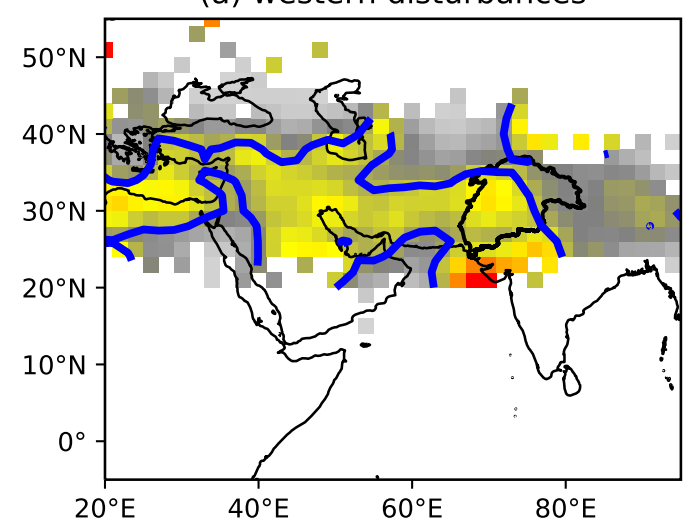

(b) tropical depressions

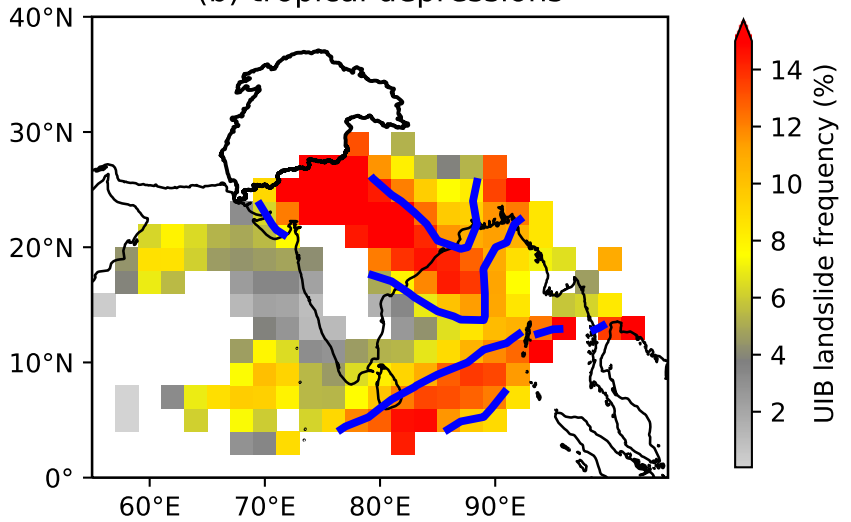

Figure 4: Mean likelihood of a landslide in the UIB, given presence of (a) a western disturbance in October-April or (b) a tropical depression in May-September in a given $2^{\circ} \times 2^{\circ}$ gridbox. The climatological values of $5 \%$ day $^{-1}$ and $11 \%$ day ${ }^{-1}$ for October-April and May-September respectively are drawn with a solid blue line. Grid boxes with fewer than five systems in are not shown.

decreased. Systems within $3-4^{\circ}$ of $30^{\circ} \mathrm{N}$ result in a significantly increased chance of a UIB landslide, whereas those much further north, particularly beyond about $40^{\circ} \mathrm{N}$, result in a significantly decreased chance. Secondly, there are three zonal maxima in frequency at about $30^{\circ} \mathrm{E}, 50^{\circ} \mathrm{E}$, and $70^{\circ} \mathrm{E}$ respectively. This approximate wavelength of $2000 \mathrm{~km}$ corresponds to the spatial scale of WDs in the subtropical westerly jet (Rao and Srinivasan, 1969) and highlight the fact that when a WD is over, or very close to, the UIB, a younger one is often $\sim 2000 \mathrm{~km}$ upstream. It is quite possible that these upstream WDs play an important role in triggering landslides over the UIB, and we will briefly discuss this in the next section; however a full treatment of the role of coupled WD dynamics in bringing heavy precipitation to the Indus Basin is left for future work.

For monsoonal TDs (Fig. 4(b)), we see that proximity to the UIB is the most important parameter in increased landslide frequency. TDs aligned along the southern edge of the climatological monsoon trough result in UIB landslide frequencies of up to $20 \%$ day $^{-1}$. Since TDs very rarely penetrate the subcontinent as far as the Indus Basin itself, they cannot provide the rain directly; instead, they must enhance the southeasterly monsoonal moisture flux that impinges on the UIB orography. This also explains why it is preferable for them to be near the south of the typical monsoon trough location; too far north and they would direct 

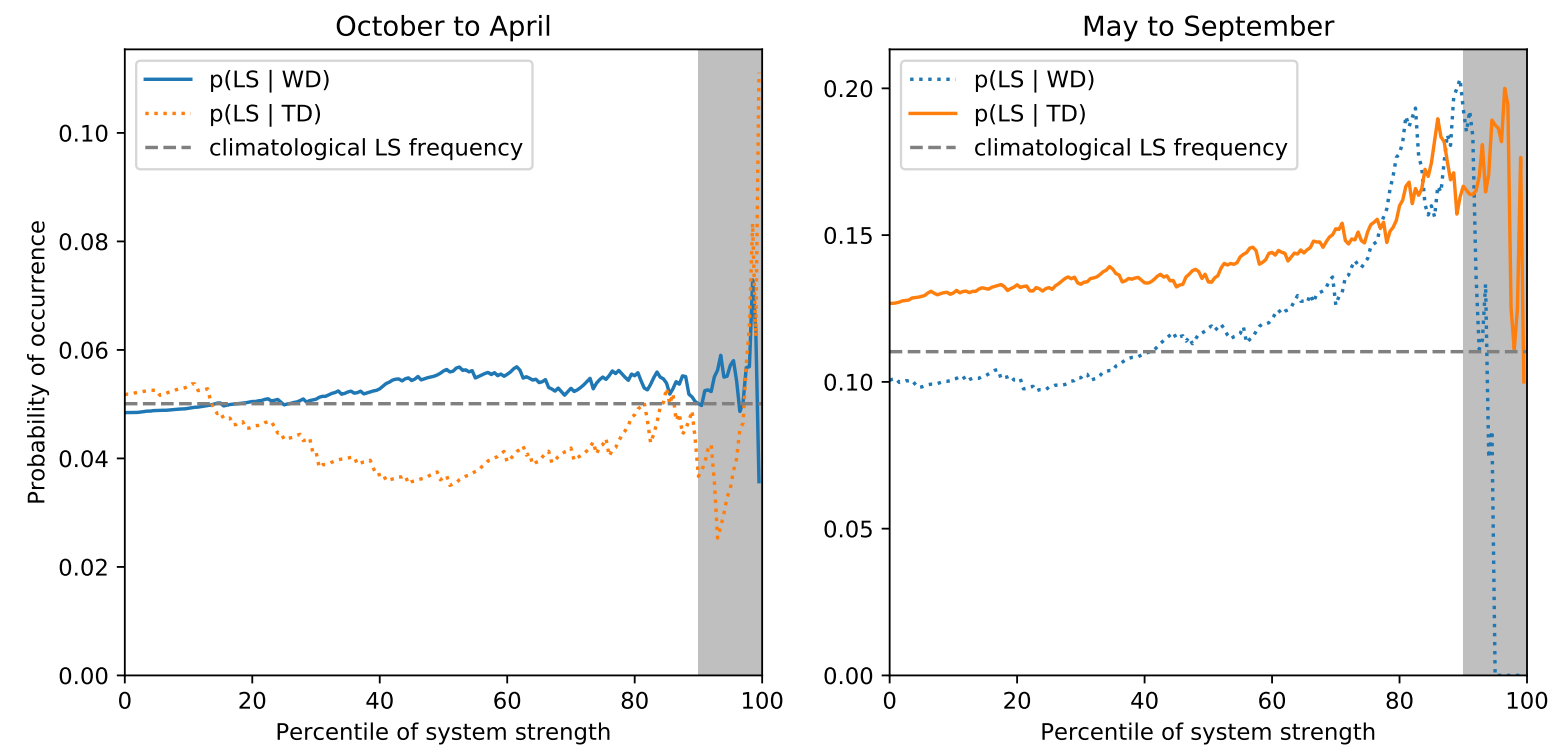

Figure 5: Change in likelihood of a landslide occurring in the UIB on a given day as a function of the intensity percentile of western disturbances (blue) and tropical depressions (orange) within $2000 \mathrm{~km}$. For each season (October-April, left; May-September, right), the rarer type of system is plotted with a dotted line. A dashed grey line marks the climatological landslide frequency for each season. The grey areas indicate where the populations of the more common system are too small for the results to be significant. Note that the $y$-axes have different scales in each subplot.

those moist southwesterlies into the central or eastern Himalaya instead. We will explore this moisture flux framework more in the next section. Of additional note are the pronounced minimum in the northeastern AS systems here would result in anomalous dry northerlies or northeasterlies passing over the Indus Basin - and the secondary maximum located towards the southern Bay of Bengal. We propose that this maximum comes about indirectly through monsoon breaks; during such periods, TD activity is highly favoured over Sri Lanka and the southern Bay of Bengal (Deoras et al., 2020), meanwhile the monsoon westerly jet is deflected north, where it impinges upon the western Himalaya. Monsoonal TDs are climatologically far less frequent in this region than over the head of the Bay of Bengal or within the monsoon trough, so this rainfall signal may not be immediately obvious. We will explore this more in the next section.

Along with system location, system intensity may also be an important control on landslide frequency.

For example, a strong low-pressure system over central India would be capable of providing much larger mois- ture flux to the Indus Basin than a very weak one. To determine this relationship, we consider only systems within $2000 \mathrm{~km}$ of the landslide, which excludes the upstream WDs and monsoon break TDs discussed previously. The probability of a landslide occurrence is then computed at each percentile of system intensity (using $850 \mathrm{hPa}$ relative vorticity for TDs and $350 \mathrm{hPa}$ relative vorticity for WDs), such that the zeroth percentile includes all systems, the fiftieth percentile includes those stronger than the median, and so on. These intensityprobability charts are shown in Fig. 5. For OctoberApril (left panel), we see that WD intensity has very little bearing on UIB landslide probability. A maximum at about the sixtieth percentile corresponds to a frequency of $5.5 \%$ day $^{-1}$, only marginally higher than the climatological value of $5 \%$ day $^{-1}$. The presence of strong TDs during the winter is, on average, detrimental to landslide probability, which falls below $4 \%$ day $^{-1}$ at the fiftieth percentile of TD intensity. This is corroborated by Fig. 4(a), since TDs are much more common in the Arabian Sea during winter than summer. During May-September (right panel), we see that TD intensity 
is strongly correlated with landslide occurrence, which is $50 \%$ higher during the passage of the most intense TDs (i.e. eightieth percentile and up) than for the average. The same is true of WDs, but they are rare during the summer months.

In summary, there is a significantly increased chance of a landslide in the UIB during winter if a WD is positioned at or around $30^{\circ} \mathrm{N}$ either over or $\sim 2000 \mathrm{~km}$ to the west of the Indus Basin. The intensity of the WD is not important. There is a significantly increased chance of a landslide in the UIB during the summer monsoon if a TD is present along the southern boundary of the climatological location of the monsoon trough, and within $2000 \mathrm{~km}$ of the basin. Stronger TDs result in a further increase in landslide probability.

\subsection{Synoptic controls on precursor pre- cipitation}

We now know that system location (and in some cases intensity) as well as precipitation is important in forecasting landslide occurrence. Here, we will now explore the relationship between the two. We start by comparing mean precipitation on days in which a landslide occurs in the UIB for instances where a TD or WD is within $2000 \mathrm{~km}$ with instances where they are not, as shown in Fig. 6. This is a relatively strict criterion, as we will see, but still gives a respectable sample size: 32 out of 116 winter UIB landslides occur with a WD within $2000 \mathrm{~km}$ and 47 out of 211 summer UIB landslides occur with a TD within $2000 \mathrm{~km}$. During winter UIB landslides (Fig. 6(a)), the presence of a local WD causes heavier precipitation over the basin as a whole, but also results in the region of heaviest precipitation moving northeastwards, penetrating deeper into the Himalayan range (see right panel). We might expect this to result in landslides also occurring deeper into the Himalaya (i.e. further to the northeast) when a WD is present, but the difference in mean landslide location between the two populations (WD present and no WD present) is not statistically significant. What are the reasons for these differences in precipitation? As discussed earlier, WDs are the major source of winter precipitation in the UIB, but there is also a considerable contribution from smaller-scale cloudbursts and localised orographic precipitation. These smaller storms do not usually result in significant moisture flux into the UIB, unlike WDs, and thus provide more isolated rainfall and snowfall, which is what we see in the right panel of Fig. 6(a). Cloudbursts have been previously been associated with cases of severe landslides in the western Himalaya (Mishra, 2015). The broad moisture flux commonly associated with WDs can penetrate further inland than the weaker, smaller-scale flux associated with cloudbursts and orographic storms, and so this may also be the reason for the enhanced upslope precipitation. WDs also bring some additional moisture along the subtropical westerly jet (e.g. Singh et al., 1981), which impacts orography at higher latitudes than southwesterly moisture flux from the AS.

During monsoonal UIB landslides (Fig. 6(b)), the presence of a nearby TD causes a significant intensification of the rainfall band along the western Himalaya compared to when one is not present. As discussed earlier, this is likely due to an intensification of the monsoon trough combined with an anomalously southern TD, resulting in anomalously large southeasterly moisture flux penetrating deep into the Indus Basin. The region of north India to the east of the Indus Basin, south of the central Himalaya, experiences simultaneous anomalous drying. It is unlikely that this is due to monsoon breaks, the secondary cause proposed earlier, as we have filtered out contributions from the more distant TDs that would be associated with this - this is in fact confirmed by extending the map southwards 

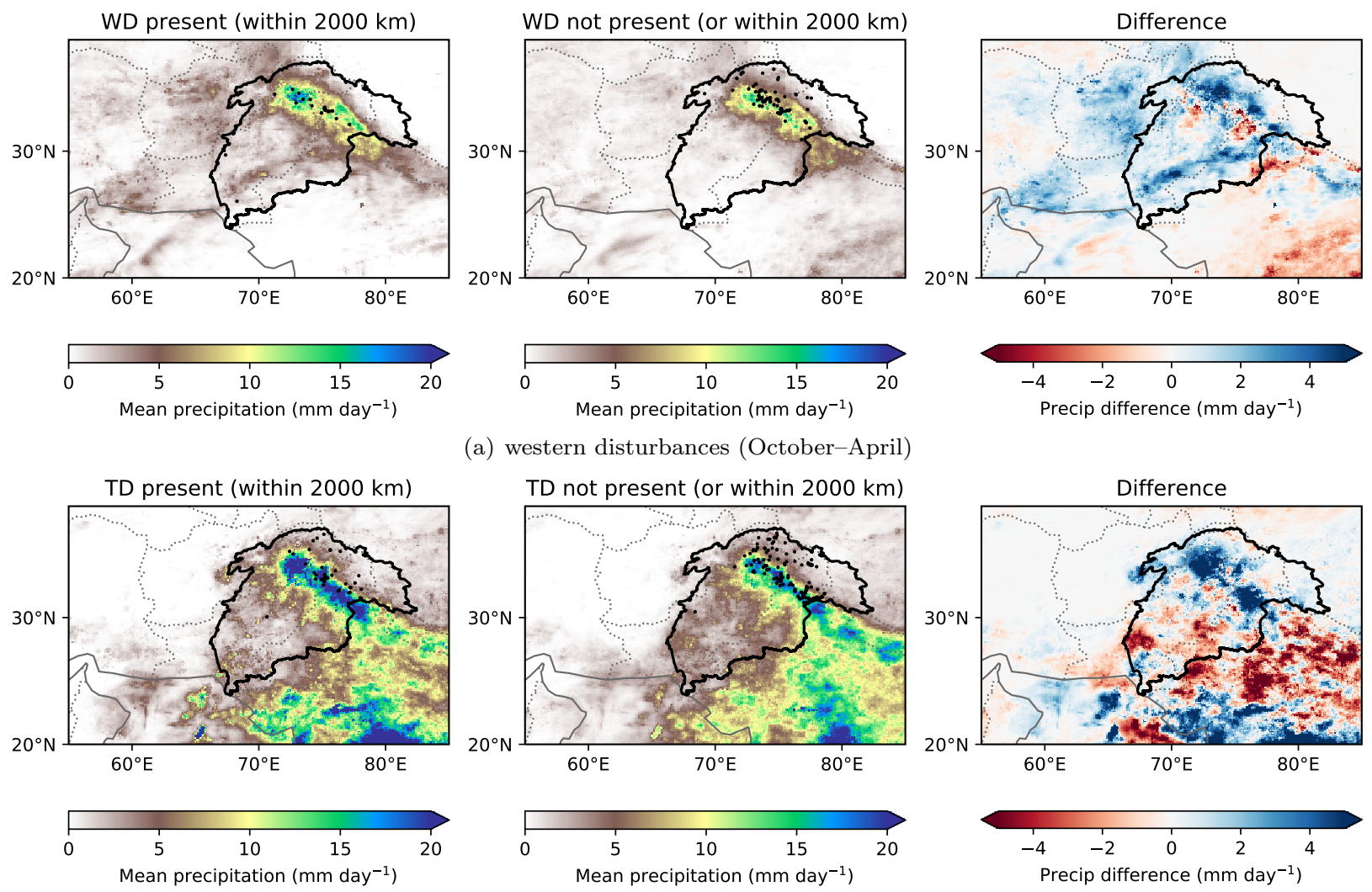

(a) western disturbances (October-April)
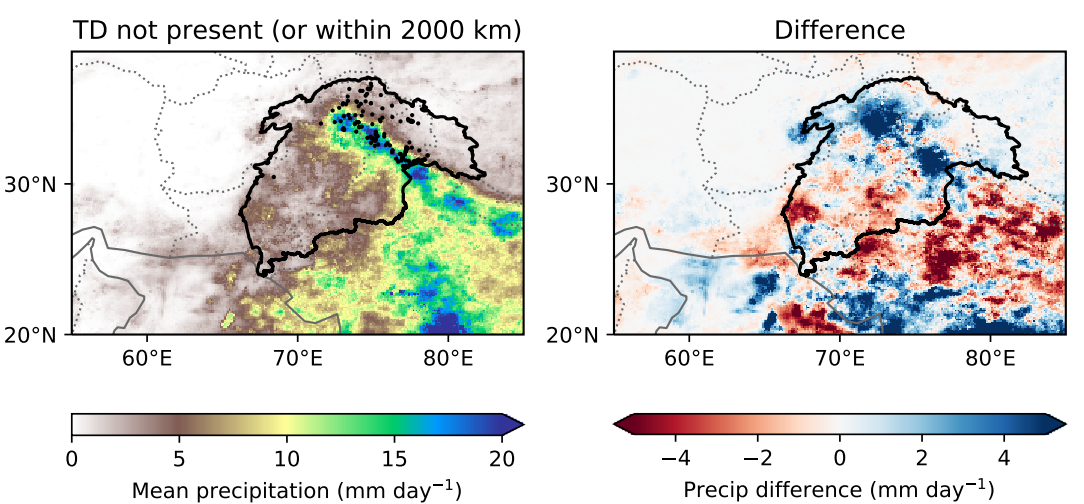

(b) tropical depressions (May-September)

Figure 6: Mean precipitation $\left[\mathrm{mm} \mathrm{day}^{-1}\right]$ on days in which a landslide occurred in the UIB in (a) October to April and (b) May to September. Separated into days where (a) a WD or (b) a TD (b) is within $2000 \mathrm{~km}$ of the landslide (left panels) and days where the respective system is either absent or farther than $2000 \mathrm{~km}$ away (middle panels). The right panels show the difference between the two. Individual landslide locations are marked with black dots. Precipitation data from GPM-IMERG.

The same figure, computed using IMDAA reanalysis, is shown in supplementary Fig. S2.

(not shown), which shows excess rainfall over much of the monsoon core zone. Instead, we propose that TDs over central India, which as we previously showed, were likely to be further south than their climatology, no longer cause moist barrier flow southeasterlies along the central Himalayan foothills; rather, they advect moisture towards the UIB from further south.

We will now test and explore these claims, and those made regarding WDs, in a moisture flux framework. Fig. 7 is constructed in the same way as Fig. 2, but instead uses vertically integrated moisture flux. The composites in Fig. 7(a) confirm our earlier hypothesis that the presence of a local WD during or immediately before a UIB landslide results in a much wider and stronger branch of westerly/southwesterly moisture flux over the Indus Basin than during its absence.
This causes more widespread precipitation and deeper penetration of moisture into the continent, and hence greater precipitation deeper into the mountain ranges, as we saw in Fig. 2(a). The scale and westward (i.e. upstream) extent of this anomalous moisture flux suggests that upstream WDs may also play an important role, though further work is needed to confirm this. We also see that during landslide days when a WD is not present (or within $2000 \mathrm{~km}$ ), there is still a significant easterly atmospheric river passing over the Indus Basin. Though it is located too far south to provide significant moisture to the foothills or mountains where landslides are most frequent, it does show evidence of northward excursions that would provide a sufficient source of moisture for cloudbursts and orographic storms, as proposed earlier.

For UIB landslides occurring during the monsoon sea- 

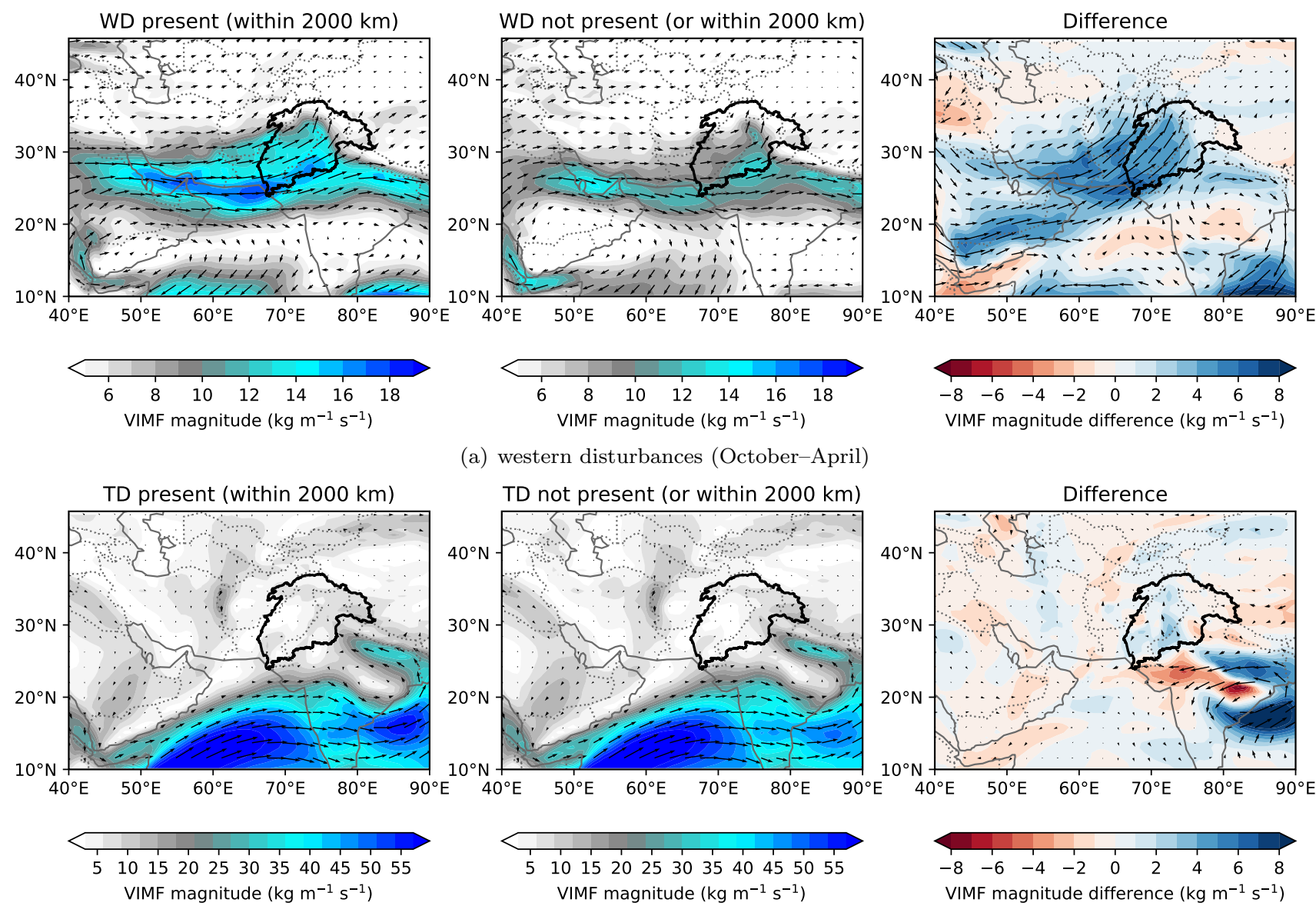

(a) western disturbances (October-April) VIMF magnitude difference $\left(\mathrm{kg} \mathrm{m}^{-1} \mathrm{~s}^{-1}\right)$

$\begin{array}{lllllll}6 & 8 & 10 & 12 & 14 & 16 & 18\end{array}$
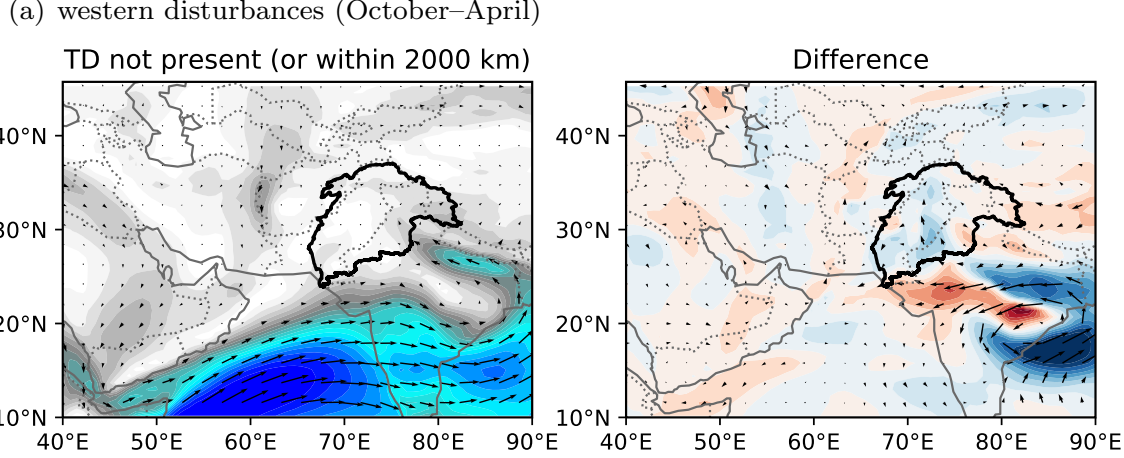

$5 \quad 10 \quad 1520 \quad 253035 \quad 4045 \quad 5055$ VIMF magnitude $\left(\mathrm{kg} \mathrm{m}^{-1} \mathrm{~s}^{-1}\right)$
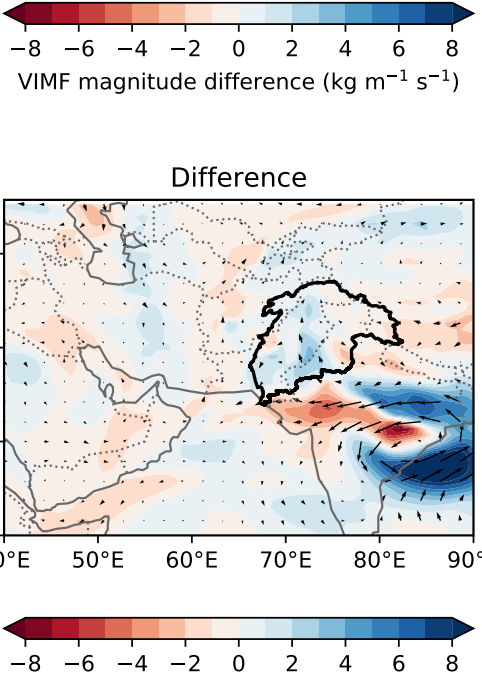

VIMF magnitude difference $\left(\mathrm{kg} \mathrm{m}^{-1} \mathrm{~s}^{-1}\right)$

(b) tropical depressions (May-September)

Figure 7: Mean vertically integrated moisture flux $\left[\mathrm{kg} \mathrm{m}^{-1} \mathrm{~s}^{-1}\right]$ on days in which a landslide occurred in the UIB in (a) October to April and (b) May to September. Arrows indicate the vector field, and coloured contours show its magnitude. As in Fig. 6, these are separated into days where (a) a WD or (b) a TD (b) is within $2000 \mathrm{~km}$ of the landslide (left panels) and days where the respective system is either absent or farther than $2000 \mathrm{~km}$ away (middle panels). The right panels show the difference between the two.

son (Fig. 7(b)), the structure of the monsoon dominates, regardless of whether a TD is present or not. Strong monsoonal westerlies bring a significant quantity of moisture over the Indian peninsula, some of which reaches the $\mathrm{BoB}$ and is subsequently directed northwestward by the monsoon trough. This results in a thin but intense stream of moisture - the so-called barrier flow - reaching the edge of the Indus Basin, enough to support thunderstorms over the western Himalaya. When a TD is present, the monsoon trough is zonally extended and deepened (right panel). Perhaps most importantly, however, the whole circulation is further south than in the non-TD composite. As we hypothesised, this reduces the barrier flow (which tends to rain out over the foothills of the central Himalaya) but en- hances southeasterly moisture flux into the Indus Basin and onto the western Himalaya and Karakoram.

We have spoken at length about precipitation occurring on the day of the landslide, which previous authors have also given the greatest importance (e.g. Dahal et al., 2008; Kirschbaum et al., 2010). However, other authors have pointed out that in addition to this, sustained antecedent rainfall, snowmelt, or runoff is required to raise the local soil moisture and reduce slope stability (Gabet et al., 2004; Kumar et al., 2014). We will now explore the relative importance of these two contributing timescales. To do this, we composite precipitation over two scales: maximum precipitation within $25 \mathrm{~km}$ of the landslide, and mean precipitation within $100 \mathrm{~km}$ of the landslide. The latter captures 


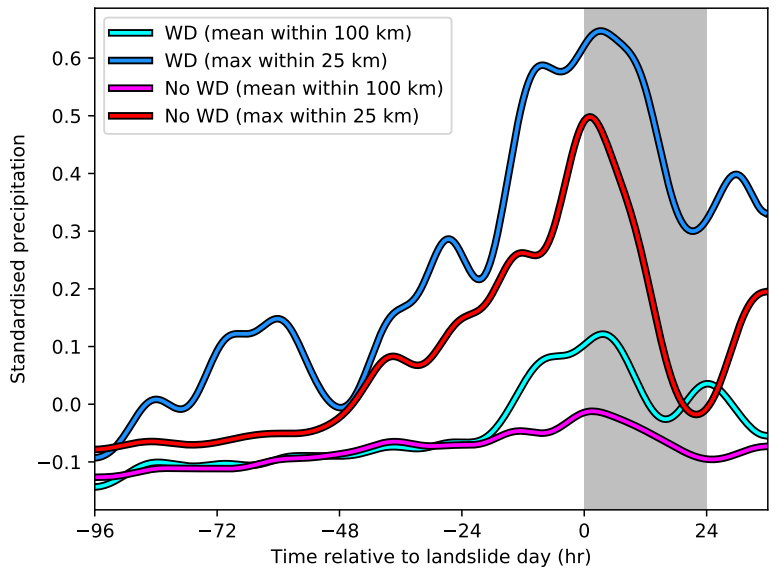

(a) October to April

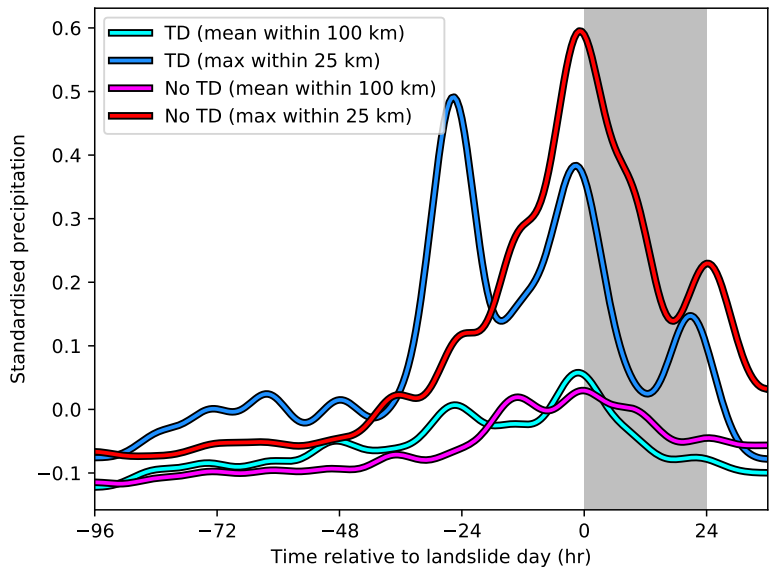

(b) May to September

Figure 8: Antecedent rainfall, computed using GPM-IMERG, for UIB landslides occurring in (a) October-April and (b) May-September. Both mean rainfall within $100 \mathrm{~km}$ of the landslide (cyan, magenta) and maximum rainfall within $25 \mathrm{~km}$ of the landslide (blue, red) are partitioned according to whether a synoptic system was (cyan, blue) or was not (magenta, red) present and within $2000 \mathrm{~km}$ of the event. The grey area indicates the 24-hour period in which the landslide occurred, aligned so that $0 \mathrm{hr}$ on the x-axis always corresponds to $0000 \mathrm{UTC}$. An 8-hour low-pass smoothing is applied to all data to reduce noise. The same figure, computed using IMDAA reanalysis, is shown in supplementary Fig. S3.

precipitation features on a larger scale (either convec-

tive or stratiform), which tend to respond to both syn-

optic dynamics and local forcing; the former captures

high intensity small-scale precipitation, which is typi-

cally convective in nature and more sensitive to local

forcing. Another reason to include two scales is the

spatial error in GPM-IMERG precipitation, which can

suffer from anvil bias in regions of large vertical wind

shear (Shrestha et al., 2015), such as south Asia under

the presence of the winter subtropical westerly jet or

monsoonal easterly upper-tropospheric jet. When con-

structing these composites, we also align the time axes

of each event such that the diurnal cycle is consistent;

that is, $0 \mathrm{hr}$ always represents $0000 \mathrm{UTC}$ on the day

in which the landslide occurs, $-12 \mathrm{hr}$ always represents

1200 UTC on the day before the landslide occurs, and

so on. This is done for two reasons: firstly, the diurnal

cycle of precipitation has considerable magnitude in the

orographic regions of south Asia (Ahrens et al., 2020)

and so it makes sense to preserve it when compositing;

secondly, precise timing of the landslide is not always

available in the NASA GLC, so we can only consistently

attach each landslide to the day, rather than the hour, in which it happened.

Fig. 8 shows the antecedent precipitation timeline for all UIB landslides in the catalogue, partitioned by season, scale, and whether a WD/TD was present and within $2000 \mathrm{~km}$. During winter landslides, the $100 \mathrm{~km}$ mean precipitation differs little from its climatology in the absence of a WD. When a WD is present, however, there is a significant increase in antecedent rainfall, starting at about 0600 UTC on the day before the landslide (i.e. -18 hours). This lends further support to our claim that non-WD winter landslides are caused by very localised events such as cloudbursts, which would have little impact on precipitation over scales of $100 \mathrm{~km}$ or so. On the smaller 25 -km scale, the WD cases again have higher precipitation rates than non-WD cases, and spread over a longer period, too: a positive anomaly in precipitation extends back three days prior to the landslide when a WD is present, but only two days when it is not. In summary, winter landslides associated with WDs receive more precipitation for longer and on a larger scale; therefore, they are likely to be more severe, given the positive correlation between antecedent rain rate and landslide fatalities (Froude and Petley, 
2018).

During summer landslides (Fig. 8(b)), the effect of a local TD is less clear than it was for WDs in the winter. This is because, as we saw in Fig. 7(b), the presence of a TD does not modulate the synoptic-scale dynamics or synoptic-scale moisture flux over the Indus Basin in the way that a WD does. Even so, there are some interesting features in the antecedent rainfall timelines. The mean rainfall within $100 \mathrm{~km}$ is never significantly higher than the climatology, regardless of whether a TD is present or not, highlighting the role of smallscale convective storms in producing the rainfall. The maximum rainfall within $25 \mathrm{~km}$ shows a very prominent diurnal cycle in both TD and non-TD cases, peaking at 0000 UTC (0530 LT), in agreement with satellite observations of the region (Sahany et al., 2010). When a TD is present, the highest rate occurs at $0000 \mathrm{UTC}$ on the preceding day, with a second, smaller peak occurring at 0000 UTC on the day of the landslide itself. For cases without a local TD, there is a singular peak, larger than for TDs, at 0000 UTC on the day of the landslide. It is not clear what the source of this difference is, but we hypothesise that a likely cause is that monsoonal TDs provide a steadier (i.e. longer-lived) source of moisture to the UIB than surges in barrier flow. High rainfall the day before the landslide means that less rainfall is then needed to trigger it on the following day. In summary, the majority of summer monsoon landslides in the UIB occur as the result of small-scale storms, whether or not a TD is present. If a TD is present, however, antecedent rainfall is considerably higher the day before the landslide, resulting in favourable conditions for one to be triggered by lighter rainfall the next day. Comparison of the results from IMDAA, shown in Fig. S3, with Fig. 8 confirms our findings. However, the reader will have noticed that the diurnal cycle of IMDAA rainfall has a much larger amplitude. Errors in this amplitude are common in models and reanalyses, such as IMDAA, that use convective parameterisation (e.g. Dirmeyer et al., 2012).

\subsection{Discussion}

One of the key research questions we asked in the introduction was whether we can improve landslide predictability through an improved understanding of the meteorology that causes episodes of heavy precipitation in the UIB. We have shown that UIB landslide frequency is highly sensitive to specific attributes of both nearby WDs and nearby TDs, such as intensity (in the case of TDs), location, and associated large-scale moisture flux patterns. Combined, these results could be of value to local forecasters looking to assess landslide risk in the UIB in short-range forecasts. This may be further improved when used in conjunction with the south Asian weather regime analysis presented in Neal et al. (2020).

One shortcoming of this work is the uncertainty introduced by the significant relationship between underlying geology (e.g., lithology, geomorphology and land use) and the relative importance of antecedent rainfall.

We are also able to make some hypotheses about how climate change will affect UIB landslides in the future, notwithstanding additional effects from deforestation or construction. Monsoonal TDs are projected to move poleward and decline in frequency Sandeep et al. (2018). Given that UIB landslides favour TDs further south than usual, both changes would contribute to a decline in summer UIB landslide risk. However, a warmer atmosphere can hold more moisture, and so heavy monsoonal precipitation that does occur over the UIB would likely be heavier still. Thus, the individual precipitation events that typically precede clusters of UIB landslides would likely become rarer but more intense.

As discussed in the introduction, the sign of change of 
future WD frequency remains a topic of debate. However, a significant poleward movement of the subtropical westerly jet would reduce winter UIB frequency, based on our results. In contrast, previous work (Hunt et al., 2020b) has shown that precipitation associated with individual winter WDs is likely to get significantly more intense in a warmer atmosphere and so, like above, we may find that the storms that cause landslides in the UIB get rarer but more intense.

The work presented here opens a number of important questions for future research, which are briefly summarised below.

- Precipitation associated with landslides is typically heavier when a WD or TD is nearby. Does this result in landslides occurring in locations that are not otherwise usually susceptible to slope instability?

- We have shown that WDs far upstream in the westerly jet can be associated with increased UIB landslide activity. They are too distant for this to be a direct effect (i.e. through moisture advection), so does their presence in a cluster result in amplification of nearer, downstream WDs?

- Landslides occurring when neither a WD or TD are present are associated with small-scale precipitation, which we have hypothesised are due to mesoscale convective systems and/or cloudbursts. What conditions increase the likelihood of such systems in the UIB? A complete inventory of convective system tracks in this region is required to improve understanding of the conditions behind nonWD, non-TD landslides.

- We speculated on the relationship of monsoon break conditions and UIB landslides, due to the secondary maximum of TD occurrence in the south of the Bay of Bengal, where they are typically found during monsoon breaks. Monsoon break conditions often bring anomalous rainfall to northwest India, but does this result in a significant increase in landslide risk in the UIB?

\section{Concluding remarks}

The objective of this study was to determine and understand the meteorological precursors to landslides in the Upper Indus Basin (UIB), a region which contains the orography of both the western Himalaya and the Karakoram. An overwhelming majority of landslides in the UIB are precipitation-triggered, rather than seismic, in nature (e.g. Froude and Petley, 2018), and so we used the NASA Global Landslide Catalogue (GLC; Kirschbaum et al., 2010, 2015), an inventory of precipitation-triggered landslides covering 2007-2015. 327 UIB landslides in this period were analysed in combination with track databases of common tropical (tropical depressions; TDs) and extratropical (western disturbances; WDs) synoptic-scale systems over south Asia (Hunt et al., 2018a; Hunt and Fletcher, 2019) to explore the underlying statistical and meteorological relationships between them. A summary of the main results follows.

\subsection{Winter: October to April}

Based on the available landslide data, and recognising the biases in the GLC, UIB landslides occur on about $5 \%$ of all winter days, peaking in February. WDs are associated, either directly or indirectly, with $61 \%$ of these. UIB landslides are significantly more common when a WD, and the subtropical westerly jet in which they are embedded, is situated within $3-4^{\circ}$ of $30^{\circ} \mathrm{N}$. WDs further north than $40^{\circ} \mathrm{N}$ significantly reduce the likelihood of a winter UIB landslide. In contrast to position, WD intensity (measured using $350 \mathrm{hPa}$ relative vorticity) does not have a significant relationship with 
UIB landslide likelihood. Analysis of composite precipitation over the days preceding and during landslides showed that winter landslides associated with WDs receive significantly more precipitation and over a longer time period than those not associated with WDs. In addition, the spatial scale of precipitation preceding nonWD landslides is significantly smaller $(<100 \mathrm{~km})$ than that of WD landslides. In both WD and non-WD landslide cases, moisture flux into the Indus Basin is predominantly westerly or southwesterly. In cases where a WD is near, the southwesterly moisture flux is significantly enhanced by the associated cyclonic winds, resulting in moisture penetrating further inland and into the mountain ranges than in non-WD cases. When a WD is not present, westerlies supply significantly less moisture to the UIB, though occasional northward excursions are sufficient to support cloudbursts and thunderstorms there.

\subsection{Summer: May to September}

UIB landslides occur on about $11 \%$ of all summer (i.e. monsoon or late pre-monsoon) days, peaking in August. TDs - used as a collective term for monsoon low-pressure systems, monsoon depressions and other synoptic-scale tropical storms - were associated with $60 \%$ of these. Landslides are significantly more common (rising to about $20 \%$ per day) when a TD is located over the centre or towards the northwest of the Indian peninsula, slightly to the south of the climatological position of the monsoon trough. The resulting deepening and southward adjustment of the trough causes strong, moist, monsoonal southeasterlies to enter the Indus Basin. For non-TD summer landslides, the required moisture flux is also provided by southeasterlies, but these take the form of an elongated barrier flow passing parallel to the Himalayan foothills, caused by a northwestward extension of the monsoon trough. In both cases, rainfall preceding the landslide has a strong diurnal cycle peaking at local dawn and is associated with relatively small-scale systems $(<100 \mathrm{~km})$, such as thunderstorms or mesoscale convective systems. TDs are associated with higher antecedent rainfall, bringing the soil closer to field capacity, and meaning that less rainfall is needed to trigger the landslide on the day itself. Unlike WDs, landslide likelihood is sensitive to TD intensity (measured using $850 \mathrm{hPa}$ relative vorticity): TDs in the 80th percentile of intensity are about $50 \%$ more likely to be associated with a UIB landslide.

\section{Acknowledgments}

KMRH is funded through the Weather and Climate Science for Service Partnership (WCSSP) India, a collaborative initiative between the Met Office, supported by the UK Government's Newton Fund, and the Indian Ministry of Earth Sciences (MoES).

\section{References}

????: Performance evaluation of latest integrated multi-satellite retrievals for Global Precipitation Measurement (imerg. 816

Ahmed, M. F., J. D. Rogers, and E. H. Ismail, 2014: A regional level preliminary landslide susceptibility study of the upper indus river basin. European Journal of Remote Sensing, 47 (1), 343-373.

Ahrens, B., T. Meier, and E. Brisson, 2020: Diurnal cycle of precipitation in the Himalayan foothillsobservations and model results. Himalayan Weather and Climate and their Impact on the Environment, Springer, 73-89.

Ashrit, R., and Coauthors, 2020: IMDAA regional re827 analysis: Performance evaluation during Indian sum798 800 804 04 805 806 808 811 5 799 801 802 803 807 809 810 812 813

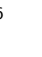

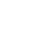

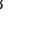


mer monsoon season. Journal of Geophysical Research: Atmospheres, 125 (2), e2019JD030 973.

Atta-ur Rehman, A. N., Khan, A. E. Collins, F. Qazi, and Coauthors, 2011: Causes and extent of environmental impacts of landslide hazard in the himalayan region: a case study of murree, pakistan. Natural Hazards, 57 (2), 413-434.

Baudouin, J.-P., M. Herzog, and C. A. Petrie, 2020: Cross-validating precipitation datasets in the Indus River basin. Hydrology and Earth System Sciences, 24 (1), 427-450.

Chevuturi, A., and A. P. Dimri, 2016: Investigation of Uttarakhand (India) disaster-2013 using weather research and forecasting model. Natural Hazards, 82 (3), 1703-1726.

Dahal, R. K., S. Hasegawa, A. Nonomura, M. Yamanaka, S. Dhakal, and P. Paudyal, 2008: Predictive modelling of rainfall-induced landslide hazard in the lesser himalaya of nepal based on weights-of-evidence. Geomorphology, 102 (3-4), 496-510.

Dee, D. P., and Coauthors, 2011: The ERA-Interim reanalysis: configuration and performance of the data assimilation system. Quart. J. Roy. Meteor. Soc., 137 (656), 553-597, doi:10.1002/qj.828.

Deoras, A., K. M. R. Hunt, and A. G. Turner, 2020: Large-scale influences on regional LPS activity over monsoonal south Asia. Weather, in review.

Dimri, A. P., 2006: Surface and upper air fields during extreme winter precipitation over the western himalayas. Pure Appl. Geophys., 163 (8), 1679-1698.

Dimri, A. P., and A. Chevuturi, 2016: Western disturbances-structure. Western DisturbancesAn Indian Meteorological Perspective, Springer, 1-26.
Dimri, A. P., A. Chevuturi, D. Niyogi, R. J. Thayyen, K. Ray, S. N. Tripathi, A. K. Pandey, and U. C. ${ }_{863}$ Mohanty, 2017: Cloudbursts in Indian Himalayas: a ${ }_{864}$ review. Earth-Science Reviews, 168, 1-23.

Dimri, A. P., D. Niyogi, A. P. Barros, J. Ridley, U. C. 866 Mohanty, T. Yasunari, and D. R. Sikka, 2015: West- ${ }^{867}$ ern disturbances: a review. Rev. Geophys., 53 (2), $225-246$.

Dirmeyer, P. A., and Coauthors, 2012: Simulating the diurnal cycle of rainfall in global climate models: Resolution versus parameterization. Climate Dynamics, 39 (1), 399-418.

Froude, M. J., and D. N. Petley, 2018: Global fatal landslide occurrence from 2004 to 2016. Natural Hazards and Earth System Sciences, 18 (8), 2161-2181.

Gabet, E. J., D. W. Burbank, J. K. Putkonen, B. A. ${ }_{877}$ Pratt-Sitaula, and T. Ojha, 2004: Rainfall thresholds for landsliding in the himalayas of nepal. Geomorphology, 63 (3-4), 131-143.

Ghosh, S., E. J. M. Carranza, C. J. van Westen, V. G. Jetten, and D. N. Bhattacharya, 2011: Selecting and weighting spatial predictors for empirical modeling of landslide susceptibility in the darjeeling himalayas (india). Geomorphology, 131 (1-2), 35-56.

Hewitt, K., 1998: Catastrophic landslides and their effects on the upper indus streams, karakoram himalaya, northern pakistan. Geomorphology, 26 (13), 47-80.

Hou, A. Y., and Coauthors, 2014: The global precipitation measurement mission. Bulletin of the American Meteorological Society, 95 (5), 701-722.

Huffman, G. J., D. T. Bolvin, E. J. Nelkin, and Coauthors, 2015: Integrated Multi-satellitE Re-

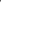


trievals for GPM (IMERG) technical documentation. NASA/GSFC Code, 612 (47), 2019.

Hunt, K. M. R., and J. K. Fletcher, 2019: The relationship between Indian monsoon rainfall and lowpressure systems. Climate Dynamics, 53 (3-4), 113.

Hunt, K. M. R., A. G. Turner, and R. K. H. Schiemann, 2020a: How interactions between tropical depressions and western disturbances enhance heavy precipitation. Monthly Weather Review, in review.

Hunt, K. M. R., A. G. Turner, and L. C. Shaffrey, 2018a: The evolution, seasonality, and impacts of western disturbances. Quart. J. Roy. Meteor. Soc., 144 (710), 278-290, doi:10.1002/qj.3200.

Hunt, K. M. R., A. G. Turner, and L. C. Shaffrey, 2018b: Extreme daily rainfall in Pakistan and north India: scale-interactions, mechanisms, and precursors. Mon. Wea. Rev., 146 (4), 1005-1022.

Hunt, K. M. R., A. G. Turner, and L. C. Shaffrey, 2019a: Falling trend of western disturbances in future climate simulations. J. Climate, 32 (16), 5037-5051.

Hunt, K. M. R., A. G. Turner, and L. C. Shaffrey, 2019b: Representation of western disturbances in CMIP5 models. J. Climate, 32 (7), doi:10.1175/ JCLI-D-18-0420.1.

Hunt, K. M. R., A. G. Turner, and L. C. Shaffrey, 2020b: The impacts of climate change on the winter water cycle of the western himalaya. Climate Dynam$i c s, 55$ (7), 2287-2307.

Kamae, Y., W. Mei, and S.-P. Xie, 2017: Climatological relationship between warm season atmospheric rivers and heavy rainfall over east asia. Journal of the Meteorological Society of Japan. Ser. II.
Kirschbaum, D., R. Adler, D. Adler, C. Peters-Lidard, and G. Huffman, 2012: Global distribution of extreme precipitation and high-impact landslides in 2010 relative to previous years. Journal of hydrometeorology, 13 (5), 1536-1551.

Kirschbaum, D., S. Kapnick, T. Stanley, and S. Pascale, 2020: Changes in extreme precipitation and landslides over high mountain asia. Geophysical Research Letters, 47 (4), e2019GL085 347.

Kirschbaum, D., T. Stanley, and Y. Zhou, 2015: Spatial and temporal analysis of a global landslide catalog. Geomorphology, 249, 4-15.

Kirschbaum, D. B., R. Adler, Y. Hong, S. Hill, and A. Lerner-Lam, 2010: A global landslide catalog for hazard applications: method, results, and limitations. Natural Hazards, 52 (3), 561-575.

Kirschbaum, D. B., R. Adler, Y. Hong, S. Kumar, C. Peters-Lidard, and A. Lerner-Lam, 2011: Advances in landslide nowcasting: evaluation of a global and regional modeling approach. Environmental Earth Sciences, 66 (6), 1683-1696.

Kozu, T., and Coauthors, 2001: Development of precipitation radar onboard the Tropical Rainfall Measuring Mission (TRMM) satellite. IEEE Trans. Geosci. Rem. Sens., 39, 102-116, doi:10.1109/36.898669, URL http://dx.doi.org/10.1109/36.898669.

Krishnan, R., T. P. Sabin, R. K. Madhura, R. K. Vellore, M. Mujumdar, J. Sanjay, S. Nayak, and M. Rajeevan, 2018: Non-monsoonal precipitation response over the Western Himalayas to climate change. Climate Dynamics, 1-19.

Kumar, A., R. A. Houze Jr, K. L. Rasmussen, and ${ }_{959}$ C. Peters-Lidard, 2014: Simulation of a flash flooding storm at the steep edge of the himalayas. Journal of Hydrometeorology, 15 (1), 212-228. 
Kummerow, C., W. Barnes, T. Kozu, J. Shiue, and J. Simpson, 1998: The Tropical Rainfall Measuring Mission (TRMM) sensor package. J. Atmos. Oceanic Technol., 15, 809-817, doi: 10.1175/1520-0426(1998)015〈0809:TTRMMT $\rangle 2$.

0.CO;2, URL http://dx.doi.org/10.1175/15200426(1998)015〈0809:TTRMMT $>2.0 . C O ; 2$.

Kummerow, C., and Coauthors, 2000: The status of the Tropical Rainfall Measuring Mission (TRMM) after two years in orbit. J. Appl. Meteor., 39 (12), 1965-1982, doi:10.1175/1520-0450(2001)040<1965: TSOTTR $>2.0 . C O ; 2, \quad$ URL http://dx.doi.org/10. 1175/1520-0450(2001)040〈1965:TSOTTR $\rangle 2.0 . \mathrm{CO} ; 2$.

Mamadjanova, G., S. Wild, M. A. Walz, and G. C. Leckebusch, 2018: The role of synoptic processes in mudflow formation in the piedmont areas of uzbekistan. Natural Hazards and Earth System Sciences, 18 (11), 2893-2919.

Mishra, A., 2015: Cloudburst and landslides in uttarakhand: A nature's fury. Mausam, 66 (1), 139-144.

Neal, R., J. Robbins, R. Dankers, A. Mitra, A. Jayakumar, E. Rajagopal, and G. Adamson, 2020: Deriving optimal weather pattern definitions for the representation of precipitation variability over India. International Journal of Climatology, 40 (1), 342-360.

Petley, D., 2012: Global patterns of loss of life from landslides. Geology, 40 (10), 927-930.

Petley, D. N., G. J. Hearn, A. Hart, N. J. Rosser, S. A. Dunning, K. Oven, and W. A. Mitchell, 2007: Trends in landslide occurrence in nepal. Natural hazards, 43 (1), 23-44.

Prakash, S., A. K. Mitra, A. AghaKouchak, Z. Liu, H. Norouzi, and D. S. Pai, 2018: A preliminary assessment of GPM-based multi-satellite precipitation estimates over a monsoon dominated region. Journal 997 of Hydrology, 556, 865-876.

Rajeevan, M., S. Gadgil, and J. Bhate, 2010: Active 999 and break spells of the indian summer monsoon. J. ${ }_{1000}$ Earth. Syst. Sci., 119 (3), 229-247. 1001

Rao, Y. P., and V. Srinivasan, 1969: Forecasting man- 1002 ual. Tech. Rep. IMD FMU Report-III 1.1, India Me- ${ }_{1003}$ teorological Department, $40 \mathrm{pp}$.

Ridley, J., A. Wiltshire, and C. Mathison, 2013: 1005 More frequent occurrence of westerly disturbances in 1006 Karakoram up to 2100. Science of The Total Envi- ${ }_{1007}$ ronment, 468, S31-S35.

1008

Sahany, S., V. Venugopal, and R. S. Nanjundiah, 1009 2010: Diurnal-scale signatures of monsoon rainfall 1010 over the Indian region from TRMM satellite observa- ${ }_{1011}$ tions. Journal of Geophysical Research: Atmospheres, 1012 115 (D2).

Saleem, J., S. S. Ahmad, A. Butt, and Coauthors, ${ }_{1014}$ 2020: Hazard risk assessment of landslide-prone sub- 1015 himalayan region by employing geospatial modeling 1016 approach. Natural Hazards: Journal of the Interna- ${ }_{1017}$ tional Society for the Prevention and Mitigation of ${ }_{1018}$ Natural Hazards, 1-18.

Sandeep, S., R. S. Ajayamohan, W. R. Boos, T. P. ${ }_{1020}$ Sabin, and V. Praveen, 2018: Decline and poleward ${ }_{1021}$ shift in Indian summer monsoon synoptic activity in 1022 a warming climate. Proc. Natl. Acad. Sci. (USA), ${ }_{1023}$ 115 (11), 2681-2686.

Sengupta, A., S. Gupta, and K. Anbarasu, 2010: Rain- ${ }_{1025}$ fall thresholds for the initiation of landslide at lanta ${ }_{1026}$ khola in north sikkim, india. Natural hazards, 52 (1), ${ }_{1027}$ 31-42.

Shrestha, D., R. Deshar, and K. Nakamura, 2015: ${ }_{1029}$ Characteristics of summer precipitation around the ${ }_{1030}$ 
Western Ghats and the Myanmar West Coast. International journal of atmospheric sciences, 2015.

Singh, M. S., A. V. R. K. Rao, and S. C. Gupta, 1981: Development and movement of a mid tropospheric cyclone in the westerlies over india. Mausam, 32 (1), $45-50$.

You, Q.-L., G.-Y. Ren, Y.-Q. Zhang, Y.-Y. Ren, X.B. Sun, Y.-J. Zhan, A. B. Shrestha, and R. Krishnan, 2017: An overview of studies of observed climate change in the Hindu Kush Himalayan (HKH) region. Advances in Climate Change Research, 8 (3), 141-147.

Zhang, J., and Coauthors, 2019: How size and trigger matter: analyzing rainfall-and earthquake-triggered landslide inventories and their causal relation in the koshi river basin, central himalaya. Natural Hazards E3 Earth System Sciences, 19 (8). 